Meta

Journal des traducteurs

Translators' Journal

\title{
La traduction, principe de perfectibilité, chez Mme de Staël
}

\section{Jane Elisabeth Wilhelm}

Volume 49, numéro 3, septembre 2004

L'histoire de la traduction et la traduction de l'histoire

History of Translation and Translation of History

URI : https://id.erudit.org/iderudit/009387ar

DOI : https://doi.org/10.7202/009387ar

Aller au sommaire du numéro

\section{Éditeur(s)}

Les Presses de l'Université de Montréal

ISSN

0026-0452 (imprimé)

1492-1421 (numérique)

Découvrir la revue

Citer cet article

Wilhelm, J. E. (2004). La traduction, principe de perfectibilité, chez Mme de Staël. Meta, 49(3), 692-705. https://doi.org/10.7202/009387ar

\section{Résumé de l'article}

Le renouveau d'intérêt, depuis une vingtaine d'années, envers les origines et le développement du libéralisme politique en Europe, l'un des courants originels de la politique moderne, a remis les écrits de Mme de Staël, de Benjamin Constant et des membres du groupe de Coppet à l'honneur. Le libéralisme apparaît aujourd'hui comme l'un des pivots de la modernité, celui à partir duquel se définissent tous les grands projets de société. En opposition au classicisme et à une conception nationaliste totalitaire promulguée par le régime de Bonaparte, Mme de Staël et ses amis entrevoient le salut des peuples et des littératures modernes dans l'échange des valeurs culturelles et artistiques. C'est le libéralisme politique traduit dans l'espace littéraire et le champ artistique. La traduction, en tant que médiation avec l'étranger, permet de révéler l'esprit national et joue un rôle capital dans la dissémination et la circulation des idées. Principe d'émulation et de commerce intellectuel, elle concourt à la perfectibilité des lettres et de l'esprit humain par l'enrichissement du caractère étranger, facteur de dynamisme social. 


\title{
La traduction, principe de perfectibilité, chez Mme de Staël
}

\author{
JANE ELISABETH WILHELM \\ Université de Genève, Genève, Suisse
}

\begin{abstract}
RÉSUMÉ
Le renouveau d'intérêt, depuis une vingtaine d'années, envers les origines et le développement du libéralisme politique en Europe, l'un des courants originels de la politique moderne, a remis les écrits de Mme de Staël, de Benjamin Constant et des membres du groupe de Coppet à l'honneur. Le libéralisme apparaît aujourd'hui comme l'un des pivots de la modernité, celui à partir duquel se définissent tous les grands projets de société. En opposition au classicisme et à une conception nationaliste totalitaire promulguée par le régime de Bonaparte, Mme de Staël et ses amis entrevoient le salut des peuples et des littératures modernes dans l'échange des valeurs culturelles et artistiques. C'est le libéralisme politique traduit dans l'espace littéraire et le champ artistique. La traduction, en tant que médiation avec l'étranger, permet de révéler l'esprit national et joue un rôle capital dans la dissémination et la circulation des idées. Principe d'émulation et de commerce intellectuel, elle concourt à la perfectibilité des lettres et de l'esprit humain par l'enrichissement du caractère étranger, facteur de dynamisme social.
\end{abstract}

\begin{abstract}
Renewed interest, over the last twenty years, in the origins and development of liberalism in Europe, one of the founding doctrines of modern politics, has sparked new study of the writings of Mme de Staël, Benjamin Constant and other members of the «Groupe de Coppet». Political liberalism would now appear to be a cornerstone of the modern world, the basis of all of society's grand projects. In opposition to French classicism and Napoleon Bonaparte's nationalist and totalitarian views, Mme de Staël and her friends foresee the future of nations and modern literatures in the light of the exchange of cultural and artistic values. This is political liberalism translated to the literary and artistic world. As a means of mediation with foreign cultures, translation helps reveal a nation's character and plays an important role in the dissemination and the movement of ideas. Translation as emulation and intellectual exchange contributes to the perfectibility of letters and of the human spirit through the wealth of other cultures, a key element of social progress.
\end{abstract}

\section{MOTS-CLÉS/KEYWORDS}

histoire de la traduction, Mme de Staël, cosmopolitisme, libéralisme politique, littérature

\section{L'espace du cosmopolitisme et du libéralisme}

Au lendemain de la Révolution, le château de Coppet sur les rives du lac de Genève, demeure d'exil de Mme de Staël, apparaît comme un carrefour ou un lieu privilégié de dialogue avec d'autres cultures: celles de l'Italie, de l'Angleterre, terre de liberté et référence obligée du libéralisme, et de l'Allemagne représentant l'idéal esthétique d'une nouvelle littérature que Mme de Staël nomme romantique. L'élite libérale, le groupe des amis de la châtelaine que la postérité a réuni sous le nom de «groupe de 
Coppet», fut dans ses grands jours, selon le mot de Stendhal, «les Etats généraux de l'opinion européenne ${ }^{1} »$. On dira à l'époque qu'il faut compter trois puissances en Europe: l'Angleterre, la Russie et Mme de Staël. Exilée à Coppet par Bonaparte qui la considère comme dangereuse, elle deviendra la figure de proue de l'opposition à la dictature impériale et l'égérie du libéralisme politique.

Le renouveau d'intérêt, depuis une vingtaine d'années, envers les origines et le développement du libéralisme, l'un des courants originels de la politique moderne en Europe et en Occident, a tiré les écrits politiques des membres du groupe de Coppet de l'oubli dans lequel ils étaient tombés durant de nombreuses années. Loin d'être uniquement une doctrine politique et économique, le libéralisme apparaît comme l'un des pivots de la modernité politique, celui à partir duquel se définissent tous les grands projets de société. Comment ont émergé et se sont articulées les notions qui vont permettre de penser et de mettre en ouvre le discours de la vie politique moderne: individu, loi et nature, société civile et État, souveraineté, représentation? En formulant le discours moderne des rapports de l'individu au sein du corps social dans l'intelligibilité d'une nouvelle figure de la liberté, Mme de Staël et Benjamin Constant se proposent de conjuguer l'ordre du politique à la littérature et à la traduction, la réflexion politique à la notion de culture nationale et aux rapports interculturels.

Lorsque disparurent les grands représentants de la philosophie des Lumières, parmi leurs héritiers, deux clans devinrent les acteurs et les témoins de la Révolution et s'attachèrent à défendre l'idéal révolutionnaire et l'idée de "perfectibilité du genre humain»: les Idéologues regroupant Cabanis, Destutt de Tracy et Volney, et le groupe de Coppet, marqué par le protestantisme et dont l'originalité est le cosmopolitisme.

Il naîtra du dialogue entre les littératures européennes, de la synthèse des idées philosophiques et de l'action politique qui caractérisent la pensée de Coppet, certaines des meilleures œuvres de l'époque. De ce vaste effort placé sous le signe des relations interculturelles et de la traduction, qui marque les débuts de la littérature comparée, il sortira au fil des années: Corinne ou l'Italie, De l'Allemagne et les Considérations sur la Révolution française de Mme de Staël, Adolphe, Cécile, Wallstein de Benjamin Constant, adaptation du Wallenstein de Schiller, la Comparaison des deux Phèdre, le Cours de littérature dramatique d'August Wilhelm Schlegel, Recherche sur la nature et les lois de l'imagination de Bonstetten, le Tableau de la littérature française au XVIII siècle de Prosper de Barante, l'Histoire des républiques italiennes et De la littérature du midi de l'Europe de Sismondi.

Benjamin Constant, qui fut l'un des principaux théoriciens du libéralisme politique sous la Restauration, fit de longs séjours au château de Coppet en compagnie de Juliette Récamier et d'August Wilhelm Schlegel. L'illustre traducteur allemand de Shakespeare, Cervantes, Calderon, Dante et Pétrarque, était aussi le précepteur des enfants de Mme de Staël. C'est autour du groupe de Coppet que s'élaborent, en deçà du partage traditionnel des connaissances, les catégories politiques, littéraires et esthétiques de la modernité. Coppet fut aussi un creuset où l'on débattait déjà des grandes questions politiques actuelles, à savoir l'unité de l'Europe dans la diversité de ses cultures, le concept de nation qui était en train de voir le jour et que l'on appelle aujourd'hui «Etat-nation», ainsi que les rapports entre l'individu et le corps social' 2 . 
"Il faut, dans nos temps modernes, " proclame Mme de Staël dans une formule restée célèbre, «avoir l'esprit européen» (1838, t. II : 151). La réflexion sur les relations interculturelles, sur l'identité d'une culture dans sa différence, s'accompagne à Coppet de la conscience qu' "une culture n'évolue que par ses contacts», selon les mots de Tzvetan Todorov, c'est-à-dire par la communication avec d'autres cultures et, comme il le dit encore «qu'en son intérieur même une culture se constitue par un travail constant de traduction» (1986: 16).

Le second mouvement du libéralisme qui va se déployer dans la première moitié du XIx ${ }^{e}$ siècle, et auquel se rattache l'œuvre de Mme de Staël et de Benjamin Constant, aura pour tâche d'interpréter tout un complexe d'idées, d'événements et de sentiments qui peut se résumer par ces mots: Rousseau et la Révolution française. Ainsi, la Révolution française est le signe par excellence d'une crise dans le corps social et politique et s'offre à leur lecture comme l'énigme d'un texte qui pose les questions centrales de la politique moderne. Dans un premier temps, il s'agit pour eux de comprendre la liberté des Modernes par rapport aux incarnations antérieures du pouvoir politique, puis de traduire ensuite l'irréductible différence de la modernité, à savoir la naissance du principe individuel par le processus révolutionnaire, au niveau des institutions politiques, sociales et littéraires.

L'historien François Furet nous parle de l'espace politique et culturel inauguré par la Révolution française, annonçant le monde de la démocratie moderne. Cet espace, qui nous investit de toutes parts, confère une sorte d'actualité permanente à tous les discours qui l'ont travaillé. La Révolution française, écrit-il, parce qu'elle est universelle et "originaire», instituant "un avant et un après, par rapport auquel s'organise une histoire qui est devenue non plus celle du prince ou de l'État, mais celle de la nation », demeure aujourd'hui encore, nous dit-il, « au centre de nos représentations politiques» et ne cesse de nous interroger (1976: 172-177).

La question fondamentale qui se posa à toute la pensée libérale française après 1789 peut se résumer ainsi: comment la Révolution française, signant le triomphe de la démocratie dans l'histoire de France et représentant l'aboutissement du progrès, présenta-t-elle ce caractère particulier d'avoir été libérale et terroriste avant d'instaurer la dictature au nom même de la liberté? Il s'agit donc pour ces libéraux qui sont des comparatistes soucieux de rapprocher l'histoire de la France à d'autres exemples, l'Angleterre et les États-Unis, non seulement d'interpréter les changements historiques, mais de parachever la Révolution par des institutions libres. Mme de Staël, fille de Jacques Necker, directeur général des finances sous Louis XVI, fut le témoin privilégié des événements de la Révolution alors que son père était à la tête du gouvernement. En reconnaissant la Révolution comme le signe ou le moment essentiel d'une histoire en marche vers la "perfectibilité de l'espèce humaine» et traversée par la «tendance vers l'égalité», Mme de Staël et Benjamin Constant cherchent à instaurer un gouvernement fort capable d'assurer la liberté en France par l'établissement d'un régime représentatif. L'achèvement de la Révolution ne fait qu'un avec la représentation, et celle-ci est la grande innovation de la politique moderne allant de pair avec le triomphe historique de l'idée d'égalité et du principe de l'individualité. La définition de la Révolution «comme crise essentielle et nécessaire qui attend de trouver sa juste traduction constitutionnelle», selon l'heureuse expression de Michel Delon (1988: 47), trouvera une réponse dans l'Acte additionnel aux Constitutions de l'Empire (connu sous le nom de «Benjamine») que Constant rédigea en 1815. 
Alors que Mme de Staël publie en 1816 dans une revue milanaise, la Biblioteca italiana, un essai intitulé De l'esprit des traductions écrit au cours de son second voyage en Italie, Benjamin Constant signe en 1813 son traité De l'esprit de conquête et de l'usurpation dans leurs rapports avec la civilisation européenne dénonçant la volonté de puissance napoléonienne comme étant antinomique au monde moderne. Sous le feu de l'actualité, l'alternative qui s'offre aux yeux de ces deux héritiers des Lumières est celle-ci: il y a, d'une part, le cosmopolitisme ou l'«esprit de traduction» favorisant le libre commerce des idées, l'échange, et le dialogue avec l'étranger, ou, d'autre part, l'«arbitraire» de l' «esprit de conquête» qui transparaît sous le régime napoléonien que dénonce Constant. Ce qui effraie ces libéraux, c'est l'hégémonie de l'État moderne dans sa version despotique impériale, à savoir la systématisation d'un pouvoir central visant à contrôler l'information et le commerce et à régler le détail de la sphère privée de l'individu. En opposition à une volonté d'uniformisation promulguée par la dictature militaire qui va de pair avec la conception totalitaire d'un État centralisé, Mme de Staël, Benjamin Constant et leurs amis entrevoient le salut des peuples et des littératures modernes dans l'échange des valeurs culturelles et artistiques nationales. C'est le libéralisme politique traduit dans l'espace littéraire et le champ artistique. "Bonaparte», note Constant en soulignant le désir impérial de résorber la liberté individuelle sous le pouvoir de la loi, «aimait la discipline partout, dans l'administration, dans l'armée, dans les écrivains, et la soumission de ces derniers n'était ni la moins prompte ni la moins empressée» (1957: 881-882).

$\mathrm{Au}$ moment où la voix de la France couvrait toutes les autres en Europe, les membres du groupe de Coppet opposent à l'hégémonie du pouvoir impérial la force d'une nation basée sur sa géographie, son histoire et ses traditions. La littérature moderne, soustraite à l'imitation de l'Antiquité qui marque le classicisme de l'Ancien Régime, ne prendra plus naissance sous l'autorité des grands modèles car elle sera désormais la voix même du peuple et du poète, la manifestation de l'inspiration et l'expression du génie. La nouvelle littérature apparaît alors inséparable d'une préoccupation d'ordre philosophique. Pour Mme de Staël, l'intérêt accordé à l'écoute d'une parole étrangère, appelant ainsi un nouveau régime de la traduction, définit un nouveau mode de la critique littéraire fondé non plus sur les règles de la bienséance, mais sur la sympathie, l'émotion et l'enthousiasme.

À la fin du Premier Empire, elle décrit dans De l'Allemagne l'idéal du cosmopolitisme et de la libre circulation des idées qui caractérisent l'esprit de Coppet:

Les nations doivent se servir de guide les unes aux autres, et toutes auraient tort de se priver des lumières qu'elles peuvent mutuellement se prêter. Il y a quelque chose de très singulier dans la différence d'un peuple à un autre: le climat, l'aspect de la nature, la langue, le gouvernement, enfin surtout les événements de l'histoire, puissance plus extraordinaire encore que toutes les autres, contribuent à ces diversités, et nul homme, quelque supérieur qu'il soit, ne peut deviner ce qui se développe naturellement dans l'esprit de celui qui vit sur un autre sol et respire un autre air: on se trouvera donc bien en tout pays d'accueillir les pensées étrangères; car, dans ce genre, l'hospitalité fait la fortune de celui qui reçoit. (Mme de Staël 1838, t. II : 161-162)

Comme ses amis, Mme de Staël comprenait fort bien que la recherche de l'identité nationale et culturelle au niveau individuel ou collectif, le rapport à soi-même et le retour aux racines dont se prévalent les mouvements nationalistes, demeurent inféconds s'ils ne s'accompagnent de l'expérience de l'altérité et d'un respect profond 
pour tout ce qui est étranger. La reconnaissance réciproque de la différence entre les peuples, ancrés dans leur situation géographique particulière et leurs traditions historiques, est la condition même d'un échange et de leur communication réciproque.

En attirant l'attention sur la profondeur philosophique et individualiste de la littérature allemande qu'elle oppose à l'aspect superficiel et frivole des lettres françaises, Mme de Staël postule la relativité du goût et met fin à l'hégémonie classique française. La littérature française est menacée de mort, s'écrie-t-elle, si elle ne trouve pas d'autre source d'inspiration que l'imitation des Anciens.

\section{Traduction et perfectibilité}

L’un des grands mérites de Mme de Staël, fut d'avoir été l'une des premières à examiner le rapport entre les institutions politiques, sociales et religieuses et la littérature. Elle pose comme principe que la littérature est l'expression de la société et, fidèle à l'héritage des Lumières ainsi qu'aux thèses de Turgot et de Condorcet, elle applique l'idée de perfectibilité à la littérature, conception nouvelle à l'époque 3 . L'étude de la «littérature», comprise ainsi dans son acception la plus large, comprend à proprement parler l'étude de l'être humain, de ses mœurs selon le modèle de Montesquieu, de son histoire, de sa philosophie et de ses institutions sociales.

La traduction en tant que principe d'émulation et de commerce intellectuel, facteur par excellence de dynamisme social, concourt à la perfectibilité des lettres et de l'esprit humain. Et fidèle à l'idéal d'une esthétique de la singularité du "génie », elle écrit dans De l'esprit des traductions:

Il n'y a pas de plus éminent service à rendre à la littérature, que de transporter d'une langue à l'autre les chefs-d'œuvre de l'esprit humain. Il existe si peu de productions du premier rang; le génie, dans quelque genre que ce soit, est un phénomène tellement rare, que si chaque nation moderne en était réduite à ses propres trésors, elle serait toujours pauvre. D'ailleurs, la circulation des idées est, de tous les genres de commerce, celui dont les avantages sont les plus certains. (Mme de Staël 1838, t. II : 294)

Si la Révolution a changé le mode d'inscription de l'individu au sein du corps social en instaurant les bases de la liberté civile, elle a également défini de nouveaux rapports entre la littérature et le pouvoir politique. "J'aurais dû pressentir qu'une révolution politique entraînerait une révolution littéraire", note à ce propos Benjamin Constant (1957: 881). Pour fonder un esprit nouveau dans l'opinion et créer des institutions modernes, il s'avère nécessaire, selon lui, d'avoir recours aux écrivains qui sont les interprètes privilégiés des signes des temps. Mme de Staël n'aura de cesse, elle aussi, de rappeler la vocation politique de l'écrivain qui se doit de mettre son talent au service de la liberté. La passion volontaire d'un discours terroriste ayant détourné la Révolution de son but véritable, ce n'est pas l'idéal révolutionnaire qu'il faut accuser, selon Mme de Staël, c'est l'absence d'une opinion publique éclairée dirigeant le pays. Le remède aux maux de la France se trouve alors dans le progrès des Lumières par la plume et l'éloquence qui feront obstacle à l'usurpation politique. La littérature philosophique, réunion du raisonnement et de l'éloquence, aux yeux de Mme de Staël, contribuera ainsi au maintien de la liberté.

Pour favoriser les progrès des Lumières et de la pensée, et garantir ainsi la liberté grâce à une opinion publique éclairée, il convient non pas d'imiter, écrit Mme de 
Staël dans son traité sur la traduction, mais d' «emprunter», afin de «connaître» et «de s'affranchir de certaines formes convenues» qui bannissent "toute vérité naturelle» de la littérature $(1838$, t. II : 296). Les transferts culturels facilitent le passage du singulier à l'universel au sein du réseau d'échanges de la culture du cosmopolitisme. Dans sa vision de la perfectibilité, la traduction contribue à ses yeux à l'essor des lettres par la connaissance d'autres cultures européennes et à la renaissance de la littérature française tout entière par le renouveau des sources d'inspiration grâce à la médiation de l'étranger:

Lors même qu'on entendrait bien les langues étrangères, on pourrait goûter encore, par une traduction bien faite dans sa propre langue, un plaisir plus familier et plus intime. Ces beautés naturalisées donnent au style national des tournures nouvelles et des expressions plus originales. Les traductions des poètes étrangers peuvent, plus efficacement que tout autre moyen, préserver la littérature d'un pays de ces tournures banales qui sont les signes les plus certains de sa décadence. (Mme de Staël 1838, t. II : 294)

Les expressions «beautés naturalisées », «tournures nouvelles» et "expressions originales» annoncent une nouvelle sensibilité esthétique en traduction dont la condition essentielle est l'esprit de liberté. Les mots «original» ou "originalité», dans l'imaginaire staëlien, renvoient à la nature primitive d'une typologie nationale, à un état de nature comme celui de Rousseau où le naturel est synonyme pour elle de vérité, de diversité et de couleurs. La traduction, dans la mesure où elle est véritablement création et non pas simplement imitation, contribue ainsi à renforcer l'identité nationale. C'est en puisant dans la richesse d'autres peuples qu'une littérature nationale peut se renouveler en permettant à de nouvelles formes culturelles de voir le jour. La théorie de la traduction, comme les rapports entre langue et culture pour Mme de Staël, sont tributaires d'une certaine conception de la nation, et l'art et la pratique de la traduction, qui est médiation à ses yeux, permet à une nation de devenir pleinement elle-même.

Dénonçant dans l'essai sur les traductions l'école du XviII ${ }^{\mathrm{e}}$ siècle des «belles infidèles ", elle met les Italiens en garde contre les contraintes d'un néo-classicisme qui les gardent emmurés dans leur passé en les invitant à s'ouvrir aux influences européennes:

Mais, pour tirer de ce travail un véritable avantage, il ne faut pas, comme les Français, donner sa propre couleur à tout ce qu'on traduit; quand même on devrait par là changer en or tout ce que l'on touche, il n'en résulterait pas moins que l'on ne pourrait pas s'en nourrir; on n'y trouverait pas des aliments nouveaux pour sa pensée, et l'on reverrait toujours le même visage avec des parures à peine différentes ${ }^{4}$. (Mme de Staël 1838, t. II : 294)

L'art de traduire, pour Mme de Staël, consiste à pratiquer ce que Paul Ricœur appelle l'«hospitalité langagière» (2004: 43) en s'efforçant de ne pas simplement transposer des pensées étrangères dans un moule français en réduisant l'autre au sein d'une culture hégémonique, mais d'en saisir le sens singulier, la tonalité et l'énergie. L'œuvre étrangère ne saurait plus être considérée comme étant barbare car elle doit désormais être reconnue dans sa différence et son originalité. L'idée de la traduction comme acte illustrant de façon privilégiée les échanges ou le «commerce» intellectuel se trouve également formulée à la même époque chez Friedrich Schleiermacher et Goethe, pour qui elle est liée au concept de Bildung. Vecteur d'une communication 
interculturelle et modèle de l'interprétation, la traduction illustre de manière exemplaire le problème posé par la lecture de l'espace culturel européen au début du $\mathrm{XIX}^{\mathrm{e}}$ siècle et l'" appropriation» de tout ce qui est étranger.

\section{Critique et traduction}

L'appel de l'étranger dans un espace de dialogue, la circulation des idées grâce à la médiation de la traduction, le voyage ou le passage entre les cultures, sont de l'ordre du mouvement ou de l'expansion du génie, non pas de l'esprit de domination ou de l'annexion à la manière de Bonaparte. La fidélité en traduction, pour Mme de Staël, consiste non pas dans l'imitation servile ou la réduction de la parole d'autrui aux critères esthétiques de sa propre culture, mais dans la faculté de faire revivre le génie créateur ou d'éveiller l'écho de l'original.

Traduire un poète, ce n'est pas prendre un compas, et copier les dimensions de l'édifice; c'est animer du même souffle de vie un instrument différent. On demande encore plus une jouissance du même genre que des traits parfaitement semblables. (Mme de Staël 1838, t. II : 296)

La critique littéraire, à laquelle se rattache l'art de la traduction aux yeux de Mme de Staël, a d'abord pour mission de «faire revivre le génie créateur » individuel ou national (1838, t. II : 159). Dès les Lettres sur les écrits et le caractère de Jean-Jacques Rousseau, qui marquent les débuts littéraires de Mme de Staël, les différents moments de la critique traditionnelle, l'examen scrupuleux et le jugement pesé dont le point culminant est l'expression d'admiration, sont d'emblée inversés. L'expérience ultime de la lecture, pour Mme de Staël, est celle d'une union totale où s'abolit momentanément toute séparation entre le lecteur et l'auteur. L'acte d'admiration rejoint alors la subjectivité créatrice et se confond avec elle dans un mouvement de fusion passionnel. Le parcours critique, s'attachant à la «description animée des chefs-d'œuvre» (Mme de Staël 1838, t. II : 159), consiste pour elle à s'absorber par la sympathie ou l'élan d'identification dans l'intimité de la pensée créatrice. La compréhension, inexorablement liée à la passion, représente, dans un premier temps, la poursuite progressive d'une complicité totale. "Car l'admiration », explique Georges Poulet en parlant de l'activité critique de Mme de Staël, «n'a de cesse qu'elle ait atteint une identification, non pas certes avec l'objet admirable, mais avec le génie même qui, par un acte interne, sui generis, fait exister cet objet» (1966:28). Comprendre, c'est se transporter dans une autre vie. L'épanchement par l'effet de la sympathie, l'un des liens originels sur lequel reposerait la société (Mme de Staël 1838, t. I: 41), devient alors un principe universel d'expansion.

Qu'elle soit littéraire, politique ou sociale, ou qu'elle s'attache à l'art de la traduction, la critique staëlienne est d'abord une «philosophie réflexive» selon l'expression de Paul Ricœur ${ }^{5}$ (1986: 152). Le sens, pour Mme de Staël, est un segment de la compréhension ou de la connaissance de soi; il est lié à la réflexion sur soi au niveau individuel ou culturel. Dans le jeu de la distance à l'autre, à savoir l'étranger, et de la réflexion sur soi, l'esthétique du génie permet au sujet de passer de sa forme originelle incomplète à la révélation d'un sens nouveau. Mme de Staël est le porte-parole d'un nouveau mode de création littéraire exaltant la liberté individuelle, le romantisme, qui appelle à son tour une nouvelle théorie de la traduction et un nouveau 
genre de critique littéraire. Elle tente de se comprendre elle-même par l'intermédiaire de la littérature du Nord ou de l'«école germanique» (la littérature de la «perfectibilité») en invitant désormais l'écrivain à puiser son talent dans le fond de son âme ${ }^{6}$. Mme de Staël est à l'écoute de l'intériorité de l'Allemagne, comme elle est à l'écoute de l'âme et du centre affectif de Rousseau ou de l' "inspiration» qui doit présider pour elle à toute traduction d'une œuvre littéraire. L'empathie dictée par l'«enthousiasme» lui permet de retrouver la «source intérieure tarie» (Mme de Staël 1838, t. II : 175) de la littérature française. Elle ne commet toutefois pas l'erreur de dire aux Français: "Faites-vous Allemands», car l'imitation à ses yeux est stérile, mais elle leur dit de retrouver leur propre richesse par l'intermédiaire de l'Allemagne. L'interprétation en ce sens "rapproche», "égalise», "rend "contemporain et semblable" », selon les mots de Paul Ricœur, et ceci est "véritablement rendre propre ce qui d'abord était étranger» $(1986: 153)^{7}$.

Au principe de l'imitation, Mme de Staël veut substituer celui de l'«émulation active» qui, écrit-elle dans De l'esprit des traductions, amènerait "par degrés l'originalité d'esprit et la vérité de style, sans lesquelles il n'y a point de littérature, ni peutêtre même aucune des qualités qu'il faudrait pour en avoir une» (1838, t. II : 296). Elle trouve dans la traduction de Shakespeare d'August Wilhelm Schlegel la vérité politique (c'est-à-dire "nationale») et l'idéal d'ordre éthique auquel elle aspire, à savoir la fidélité au sens (ou ce qu'elle appelle l'« exactitude») alliée à l' "inspiration» du génie. Et elle écrit:

Si les traductions des poëmes $[$ sic] enrichissent les belles-lettres, celles des pièces de théâtre pourraient exercer encore une plus grande influence; car le théâtre est vraiment le pouvoir exécutif de la littérature. A. W. Schlegel a fait une traduction de Shakspeare [sic], qui, réunissant l'exactitude à l'inspiration, est tout à fait nationale en Allemagne. Les pièces anglaises ainsi transmises sont jouées sur le théâtre allemand, et Shakspeare [sic] et Schiller y sont devenus compatriotes. (Mme de Staël 1838, t. II : 296)

Benjamin Constant publie en 1817, dans le Mercure de France, les pages des Réflexions sur la tragédie consacrées à l'esthétique du théâtre français et allemand avec une introduction où il annonce un «commencement de révolution dans notre littérature ». Il envisage l'avenir de la production théâtrale à la lumière de l'analyse qu'il fait des institutions modernes:

Dans les pays libres, les caractères sont beaucoup plus intéressants que les passions. Les passions ne forment que des épisodes dans la vie des individus. Les caractères décident de la destinée des peuples. D'après nos institutions actuelles, il me paraît certain que nos poètes seront poussés presque exclusivement vers la tragédie historique; et, dans la tragédie historique, il sera difficile de ne pas admettre en partie le système des étrangers ${ }^{8}$.

La nouvelle idée du tragique selon Constant est politique: la conscience moderne doit trouver son expression dans une esthétique qui ne peint pas seulement l'aspiration à la liberté de l'individu mais l'action de la société et de ses institutions sur celui-ci. Mme de Staël, dans De l'Allemagne, avait aussi noté que «la tendance naturelle du siècle, c'est la tragédie historique» $(1838$, t. II : 258). 


\section{Le lieu de l'exil}

L'expérience de l'exil, pour Mme de Staël, est aussi celle de l'«ouverture sur l'Étranger», écrit Antoine Berman en rappelant que l'exil, selon ses mots, "a eu une importance décisive sur la structure de la culture française» (1999: 98). Les écrits de Mme de Staël sont hantés par le thème et la figure de l'exil qu'elle compare toujours à la mort. En 1803, elle reçoit l'ordre de Bonaparte de s'éloigner à plus de quarante lieues de Paris et se trouve ainsi exclue des activités politiques et intellectuelles de la capitale. C'est alors que commence le long et douloureux exil de dix années durant lesquelles l'Empereur s'efforcera, selon l'expression de l'auteur, d' «annuler» celle qui avec Benjamin Constant avait souhaité constituer une opposition au régime impérial et contribuer à la formation d'une opinion publique éclairée. Face à l'épée, il lui reste la plume: elle s'enfuit et s'arroge le droit à la parole en écrivant le traité De l'Allemagne qui annonce le romantisme, une révolution littéraire qui sera la traduction intellectuelle d'une réaction politique, l'expression d'une pensée basée sur le respect de l'individualisme et de l'étranger. En s'opposant à un discours politique totalitaire assimilant l'hégémonie française à l'universel, Mme de Staël souligne la nécessité de la différence et de l'altérité comme composantes légitimes et nécessaires de tout état de société ou de tout système de pensée.

La censure impériale ordonna la mise au pilon du livre De l'Allemagne en 1810. L'Empereur fit savoir par l'intermédiaire de son ministre de la police, le duc de Rovigo: «Nous n'en sommes pas encore réduits à chercher des modèles dans les peuples que vous admirez. Votre dernier ouvrage n'est point français » (Mme de Staël 1968, t. 1: 30). Sommée de livrer ses manuscrits, Mme de Staël est condamnée au silence. La répression persiste: tous ceux qui cherchent à rompre le silence de l'exil du château de Coppet sont à leur tour bannis. Barante, le préfet de Genève, qui se montre trop indulgent à l'égard de la châtelaine est déplacé; Mme Récamier à son tour exilée.

Mme de Staël ne pensait pourtant pas qu'elle allait offenser le pouvoir impérial mais le livre entier était fait pour déplaire, à commencer par son objet principal: donner aux Français l'exemple d'un autre peuple comme modèle culturel. De l'Allemagne, cependant, joua un rôle politique important en Europe car son interdiction par la censure napoléonienne était la démonstration même de la dictature impériale.

La condamnation du livre De l'Allemagne fut pour Mme de Staël un coup terrible, car la censure signifiait l'interdiction de toute autre publication à l'avenir. Elle décide alors de publier malgré tout et de s'enfuir. Espérant gagner la Suède puis l'Angleterre, patrie du libéralisme, il ne lui reste qu'une seule route de libre, celle de Vienne et de Moscou, à condition toutefois de gagner de vitesse la Grande Armée. À l'instar de Bonaparte qui étudiait la carte de l'Europe en conquérant pour s'en rendre maître, Mme de Staël l'étudie pour s'enfuir, mais ils auront tous deux pour horizon la Russie où elle cherchera refuge. La traversée de l'Europe racontée dans Dix années d'exil fera d'elle l'ambassadrice de la France héritière d'une révolution libérale et démocratique ainsi que l'incarnation d'un moment de la conscience républicaine. Sur la route de l'exil, Mme de Staël jouera enfin le rôle politique dont elle avait toujours rêvé en servant de lien diplomatique entre la Russie et la Suède et plus tard l'Angleterre.

Par leur position géographique et intellectuelle marginale, les amis de Mme de Staël vivent à la dimension de l'Europe et l'exil, expérience radicale de l'altérité du 
monde, s'ouvre alors sur l'échange, l'espace des rapports et des transferts culturels. En parlant du réseau épistolaire de Coppet, Marie-Claire Hoock-Demarle souligne le "paradoxe qui oppose en chacun des étrangers de Coppet l'enracinement national et la dimension européenne» (1991 : 27). Pierre Macherey écrit aussi à propos des membres de ce groupe: «Etrangers et familiers aux genres et aux formes d'expression de plusieurs nations, ils ont contrôlé les principaux points de passage par lesquels pouvait s'effectuer à leur époque une communication culturelle.» (1990: 23) Du point de vue théorique, comme dans la pratique, ils préfigurent en quelque sorte la société moderne des réseaux avec la mise en circulation de signes et les échanges culturels par la traduction ou l'adaptation qui sont pour eux des instruments privilégiés de médiation. La culture cosmopolite de Coppet, écrit encore Pierre Macherey, transmet «des valeurs propres aux sensibilités les plus étrangères entre elles: ces valeurs se complètent, se mêlent, sans se confondre» (1990: 24). Et il explique ainsi que dans l'espace de cette ouverture «naît par la même occasion une nouvelle culture, ayant subi l'épreuve de cette migration linguistique, idéologique et poétique, qui rend possibles confrontations et échanges entre des éléments complètement étrangers entre eux à l'origine, en les mettant en rapport sur la base de leur étrangeté réciproque» (1990: 25).

La nouvelle culture issue du mariage du cosmopolitisme et du libéralisme qui voit le jour à Coppet répond à ce qu'Antoine Berman appelle une exigence ou un «choix éthique ( $1999: 75)$. «L'acte éthique », explique ce dernier, "consiste à reconnaître et à recevoir l'Autre en tant qu'Autre» (1999: 74). Et il ajoute: "Cette nature de l'acte éthique est implicitement contenue dans les sagesses grecque et hébraïque, pour lesquelles, sous la figure de l'Étranger (par exemple du suppliant), l'homme rencontre Dieu ou le Divin» (1999: 74-75).

L'origine protestante d'un grand nombre de ses membres permet de comprendre l'un des aspects originaux du groupe de Coppet, à savoir l'alliance des Lumières et de la foi. Par ses origines familiales, Mme de Staël appartient à un milieu où «lumières » et «religion» ne sont pas tenues pour incompatibles. Elle est issue d'une lignée de pasteurs et de protestants libéraux très attachée à la tradition du christianisme réformé. À l'instar de Mme de Staël, Constant s'oppose au matérialisme du XviII ${ }^{\mathrm{e}}$ siècle et à l'utilitarisme de Bentham qui lui paraissent être des impasses de la pensée philosophique ne pouvant légitimer l'instauration d'un nouvel ordre social. Si l'autorité de l'histoire montre la nécessité rationnelle de la liberté civile, à ses yeux, la défense des droits de l'individu relève en définitive d'une exigence éthique que Constant pose hors de toute rationalité politique. L'éthique et le religieux seront les mobiles et les auxiliaires du politique dans une société révolutionnée.

Ainsi la traduction, instrument privilégié de communication entre les cultures, de pouvoir et de commerce intellectuel pour Mme de Staël, appartient selon Berman « originairement à la dimension éthique » par sa «visée de fidélité » (1999: 75). Et celuici écrit encore à propos de la traduction: «Elle est, dans son essence même, animée du désir d'ouvrir l'Étranger en tant qu'Étranger à son propre espace de langue» (1999: 75). L'expérience de l'étranger, dans la vie et l'œuvre de Mme de Staël, n'est jamais celle de la simple soumission d'autrui dans un rapport de domination comme celui qu'elle dénonce chez Bonaparte. L'étranger, pour elle, a une fonction de révélation de l'esprit national ou de médiation et c'est par la traduction ou l'adaptation des œuvres littéraires que se manifeste de manière privilégiée la communication entre les cultures. 
Dans la lutte acharnée que se livrèrent le Premier Consul et la fille de Necker, l'empire de la littérature revint à Mme de Staël. «En politique comme en littérature», rappelle Jean Starobinski, «elle a su clairement définir une nouvelle organisation des pouvoirs». Et il écrit encore: «Dans le domaine littéraire, malgré l'hostilité du maître de la nation, ou peut-être en raison même de la persécution et de l'exil, elle a pris le pouvoir et l'a exercé assez durablement». (1989: 83) Elle a su conquérir une place de choix dans l'histoire de la traduction et demeure à jamais, dans les anthologies du traduire, celle qui fit connaître l'Allemagne à la France. Littérature, traduction et politique furent toujours inséparables à ses yeux car l'art du traduire représentaient pour elle un moyen de changement privilégié dans l'ordre esthétique, politique et social. L'œuvre et le destin de Mme de Staël nous autorisent aussi à nous poser cette question : et si la traduction n'avait pas toujours quelque chose à voir avec le pouvoir, serait-ce là alors la véritable raison de son occultation dans l'histoire occidentale? Il convenait donc de rappeler ici que les origines du libéralisme politique en Europe, représentées par le groupe de Coppet, sont indissociablement liées à une certaine conception de la culture cosmopolite et de la nation, à une théorie littéraire ainsi qu'à l'art et la pratique de la traduction.

\section{NOTES}

1. Stendhal écrit dans la première édition de Rome, Naples et Florence en 1817: «On me raconte qu'il y eut, cet automne, sur les rives du lac, la réunion la plus étonnante : c'étaient les Etats généraux de l'opinion européenne.»

2. Simone Balayé écrit que le mot «nationalité» fut inventé dans ce milieu. Voir l'article "Madame de Staël" rédigé par Simone Balayé dans le Dictionnaire Napoléon publié sous la direction de Jean Tulard.

3. Mme de Stäel a pris soin de préciser elle-même son idée: «Je ne prétends pas dire que les modernes aient une puissance d'esprit plus grande que celle des anciens, mais seulement que la masse des idées en tout genre s'augmente avec les siècles.» (Mme de Staël, Euvres complètes, T. I, p. 198). Pierre Macherey, dans son livre intitulé A quoi pense la littérature? (Paris: Presses Universitaires de France, 1990) écrit que Mme de Staël «a forgé un concept de 'littérature', terme qu'elle a été l'une des premières à utiliser dans son sens moderne» (p. 17).

4. Voir Jacques Bereaud, «La Traduction en France à l'époque romantique», Comparative Literature Studies, vol. VIII, $\mathrm{n}^{\circ} 3$, septembre 1971, p. 224-244. Celui-ci écrit qu'elle pose «le problème en termes nouveaux» (p. 227). Et il ajoute: «Mme de Staël ne faisait, en 1816, qu'énoncer un principe nouveau. Ce principe n'allait pas s'imposer immédiatement et il faudra attendre une quinzaine d'années avant de le voir accepté et surtout appliqué par la majorité des traducteurs.» (p. 228)

5. Paul Ricœur explicite ainsi ce concept: «Cet achèvement de l'intelligence du texte dans une intelligence de soi caractérise la sorte de philosophie réflexive que j'ai, à diverses occasions, appelée réflexion concrète.» (1986: 152)

6. Dans De l'Allemagne, Mme de Staël écrit: «J.-J. Rousseau, Bernardin de Saint-Pierre, Chateaubriand, etc., dans quelques-uns de leurs ouvrages, sont tous, même à leur insu, de l'école germanique, c'est-àdire qu'ils ne puisent leur talent que dans le fond de leur âme.» (1838: t. II, p.45)

7. Antoine Berman parle aussi de «féconder le Propre par la médiation de l’Etranger» (1984: 16).

8. Cité par Martine de Rougemont in "L'esthétique théâtrale de Benjamin Constant », Benjamin Constant, Madame de Staël et le Groupe de Coppet (Oxford: The Voltaire Foundation: Lausanne: Institut Benjamin Constant, 1982), p. 248.

\section{RÉFÉRENCES}

CEUVRES DE MADAME DE STAËL

STAËL, Madame de (1838): CEuvres complètes de Madame la baronne de Staël-Holstein, Paris, Firmin-Didot et Treuttel et Wurtz. 
STAËL, Madame de (1968): De l'Allemagne, Paris, Garnier-Flammarion, chronologie et introduction par Simone Balayé.

StaËL, Madame de (1979): Essai sur les fictions suivi de De l'influence des passions sur le bonheur des individus et des nations, préface de Michel Tournier, Paris, Editions Ramsay.

\section{CRITIQUE CONSACRÉE À MADAME DE STAËL ET AU GROUPE DE COPPET}

BALAYÉ, S. (1971): Les carnets de voyage de Madame de Staël. Contribution à la genèse de ses auvres, Genève, Librairie Droz.

Balayé, S. (1978) : «Le Dossier Staël», Romantisme, no 20.

Balayé, S. (1979) : Madame de Staël, lumières et liberté, Paris, Editions Klincksieck.

Barberis, P. (1987) : «Mme de Staël: du romantisme, de la littérature et de la France nouvelle», Europe, $\mathrm{n}^{\circ}$ 693-694, p. 6-22.

Barilier, E. (1997): «Enthousiasme ou fanatisme», Travaux du Centre de traduction littéraire, Université de Lausanne, p. 57-63.

Coulet, H. (1987) : «Révolution et roman selon Madame de Staël», Revue d'histoire littéraire de la France, no ${ }^{\circ}$ 4, p. 638-660.

Delon, M. (1985): "Un exil moderne», Magazine littéraire, n² 221, p. 18-19.

Delon, M. (1988) : «Staël, Constant: les premiers théoriciens», Magazine littéraire, n 258, p. 4647.

Delon, M. (1997) : «Le Défi de Coppet», Travaux du Centre de traduction littéraire, Université de Lausanne, p. 49-55.

De Man, P. (1966) : «Madame de Staël et Jean-Jacques Rousseau», Preuves, nº 190, p. 35-40.

Diesbach, G. de (1983) : Madame de Staël, Paris, Librairie académique Perrin.

Didier, B. (1999) : Madame de Staël, Paris, Ellipses.

Fernande, D. (1997): «Madame de Staël contre Napoléon», Le Nouvel Observateur, 15 mai.

Gengembre, G. et J. Goldzink (1989) : «Et Mme de Staël prit le chemin de l'exil... », L'Histoire, $\mathrm{n}^{\circ} 124$, p. $44-48$.

Gengembre, G. (1990) : «Pour une littérature républicaine: des Idéologues à Madame de Staël» in Littérature et Révolutions en France, Amsterdam et Atlanta, Rodopi, p. 13-39.

Goldberger, A. H. (1994) : «Madame de Staël, De l'esprit des traductions: réflexions d'une traductrice» in Le Groupe de Coppet et l'Europe, 1789-1830, Actes du cinquième Colloque de Coppet, 8-10 juillet 1993 (Tübingen), Lausanne, Institut Benjamin Constant, Paris, Jean Touzot, p. 345-359.

Hoock-Demarle, M.-C. (1991) : «Un lieu d'interculturalité franco-allemande: le réseau épistolaire de Coppet», Romantisme, $\mathrm{n}^{\circ}$ 73, p. 20-28.

Kristeva, J. (1988): "Gloire, deuil et écriture. Lettre à un "romantique" sur Mme de Staël», Romantisme, $\mathrm{n}^{\circ}$ 62, p. 7-14.

Lozano, W. C. (1995): «De l'esprit des traductions (1816) de Mme de Staël: avatares de una reflexión sobre la traducción literaria ", Sendebar, n 6 , p. 23-38.

Macherey, P. (1990) : À quoi pense la littérature?: exercices de philosophie littéraire, Paris, Presses Universitaires de France.

Mortier, R. (1982): L'originalité. Une nouvelle catégorie esthétique au siècle des lumières, Genève, Librairie Droz.

Poulet, G. (1966) : «La pensée critique de Mme de Staël», Preuves, n 190, p. 27-35.

RaYNAUd, P. (1989): «Les femmes et la civilité: aristocratie et passions révolutionnaires», Le débat, nº 57, p. 180-185.

Rougemont, D. de (1980) : «Madame de Staël et l'esprit européen», Cahiers staëliens, t. XXVIII, p. 41-48.

Solovieff, G. (1974): Madame de Staël, choix de textes, thématique et actualité, Paris, Editions Klincksieck.

Starobinski, J. (1966) : «Mme de Staël et la définition de la littérature », La Nouvelle Revue française, p. 1054-1059. 
Starobinski, J. (1966): «Suicide et mélancolie chez Mme de Staël», Preuves, n 190, p. 41-48.

Starobinski, J. (1972): «Critique et principe d'autorité. Madame de Staël et Rousseau» in Mouvements premiers. Etudes critiques offertes à Georges Poulet, Paris, Librairie José Corti, p. 87106

Starobinski, J. (1980): «Benjamin Constant et l'éloquence», CADMOS, Cahiers trimestriels de l'Institut Universitaire d'études européennes et du Centre européen de la culture, p. 26-42.

Starobinski, J. (1989): «Madame de Staël: passion et littérature» in Table d'orientation: l'auteur et son autorité, Lausanne, L'Âge d'Homme, p. 83-110.

Todorov, T. (1986): «Le croisement des cultures», Communications 43, p. 5-24.

Todorov, T. (1997): Benjamin Constant: la passion démocratique, Paris, Hachette.

Tripet, A. (1998) : Entre Humanisme et rêverie. Études sur les littératures française et italienne de la Renaissance au Romantisme, Paris, Honoré Champion.

\section{COLLOQUES}

Benjamin Constant (1968): Actes du Congrès Benjamin Constant de Lausanne (octobre 1967), édités par Pierre Cordey et Jean-Luc Seylaz, Genève, Librairie Droz.

Madame de Staël et l'Europe (1970): Actes du premier Colloque de Coppet organisé pour la célébration du deuxième centenaire de la naissance de Madame de Staël (18-24 juillet 1966), Paris, Editions Klincksieck.

Le Groupe de Coppet (1977): Actes et documents du deuxième Colloque de Coppet (10-13 juillet 1974), publiés par la Société des études staëliennes sous la direction de Simone Balayé et de Jean-Daniel Candaux, Genève, Librairie M. Slatkine, Paris, Librairie Honoré Champion.

Benjamin Constant, Madame de Staël et le Groupe de Coppet (1982): Actes du deuxième Congrès de Lausanne et du troisième Colloque de Coppet (15-19 juillet 1980), publiés sous la direction d'Etienne Hofmann, Oxford, The Voltaire Foundation, Lausanne, Institut Benjamin Constant.

Le Groupe de Coppet et la Révolution française (1988): Actes du quatrième Colloque de Coppet (20-23 juillet), publiés sous la direction d'Etienne Hofmann et d'Anne-Lise Delacrétaz, Lausanne, Institut Benjamin Constant, Paris, Jean Touzot.

Le Groupe de Coppet et l'Europe, 1789-1830 (1994) : Actes du cinquième Colloque de Coppet, 8-10 juillet 1993 (Tübingen), Lausanne, Institut Benjamin Constant, Paris, Jean Touzot.

\section{CEUVRES DE BENJAMIN CONSTANT}

Constant, B. (1957): Euvres, texte présenté et annoté par Alfred Roulin, Paris, Editions Gallimard, «Bibliothèque de la Pléiade».

Constant, B. (1964) : Écrits et discours politiques, présentation, notes et commentaires par O. Pozzo di Borgo, Paris, Éditions Jean-Jacques Pauvert.

Constant, B. (1965): Wallstein: tragédie en cinq actes et en vers, édition critique publiée avec de nombreuses variantes et des documents inédits par Jean-René Derré, Paris, Société d'édition «Les Belles-Lettres».

Constant, B. (1980): Principes de politique applicables à tous les gouvernements, texte établi d'après les manuscrits de Lausanne et de Paris avec une introduction et des notes par Etienne Hofmann, Genève, Librairie Droz.

Constant, B. (1986) : De l'esprit de conquête et de l'usurpation dans leurs rapports avec la civilisation européenne, introduction, notes, bibliographie et chronologie par Ephraïm Harpaz, Paris, Garnier-Flammarion.

\section{THÉORIE DE LA TRADUCTION}

Benjamin, W. (1971): Euvres I, essais traduits de l'allemand par Maurice de Gandillac, Paris, Les Lettres Nouvelles.

Bereaud, J. (1971): «La traduction en France à l'époque romantique», Comparative Literature Studies, vol. VIII, n 3, p. 224-244. 
Berman, A. (1984): L'épreuve de l'étranger. Culture et traduction dans l'Allemagne romantique, Paris, Éditions Gallimard.

Berman, A. (1993): "La Traduction et ses Discours» in La traduction dans le développement des littératures, Berne et Berlin, Peter Lang, p. 39-48.

Berman, A. (1995): Pour une critique des traductions: John Donne, Paris, Éditions Gallimard.

Berman, A. (1999): La traduction et la lettre ou l'auberge du lointain, Paris, Éditions du Seuil.

D'Hulst, L. (1990): Cent ans de théorie française de la traduction. De Batteux à Littré (17481847), Lille, Presses Universitaires.

D'Hulst, L. (1993) : «La traduction en France à l'époque romantique et l'évolution de la culture française» in La traduction dans le développement des littératures, Berne et Berlin, Peter Lang, p. 159-164.

Horguelin, P. (1981): Anthologie de la manière de traduire, Montréal, Linguatech.

Lefevere, A. (1992): Translation, Rewriting and the Manipulation of Literary Fame, New York, Routledge.

Simon, S. (2001): "Antoine Berman ou l'absolu critique», Traduction Terminologie, Rédaction (TTR), vol. XIV, no 2, p. 19-29.

Simon, S. (2002) : "Germaine de Staël and Gayatri Spivak: Culture Brokers» in M. Tyмосzко \& E. Gentzler, Translation and Power, Amherst et Boston, University of Massachusetts Press, p. $122-140$.

Steiner, G. (1975) : After Babel. Aspects of Language and Translation, London, Oxford University Press.

\section{AUTRES}

Furet, F. (1976) : «Au centre de nos représentations politiques», Esprit, no 460, p. 172-178.

Furet, F. (1986): «Penser la Révolution française», Magazine littéraire, n 228, p. 92-97.

JaRdin, A. (1985): Histoire du libéralisme politique de la crise de l'absolutisme à la constitution de 1875, Paris, Hachette.

Manent, P. (1986): Les libéraux, Paris, Librairie Hachette, collection «Pluriel».

Manent, P. (1987): Histoire intellectuelle du libéralisme: dix leçons, Paris, Calmann-Lévy.

Ricceur, P. (1986): Du texte à l'action. Essais d'herméneutique II, Paris, Editions du Seuil.

Ricceur, P. (1999): «Le paradigme de la traduction», Esprit, p. 8-19.

Riccur, P. (2004): Sur la traduction, Paris, Bayard.

Stendhal (1960): Rome, Naples et Florence en 1817, préface et notes de Victor Del Litto, Lausanne, Editions Rencontre.

Todorov, T. (1986) : «Le croisement des cultures», Communications 43, p. 5-24.

Tulard, J. (1987): Dictionnaire Napoléon, Paris, Editions Fayard. 